\title{
Improving Communication about Limit Concept in Mathematics through Inquisition and Replication
}

\author{
Kailas Shankarrao Borase ${ }^{1}$, S.P.Pethe ${ }^{2}$ S.M.Khairnar ${ }^{3}$ \\ ${ }^{I}$ Department of Mathematics, RNC Arts, JDB Commerce and NSC Science College, Nasik Road, Maharashtra \\ (India), ${ }^{2}$ Premsagar Society, Nasik (M.S.), ${ }^{3}$ Head,R.\&D.MIT,Alandi,Pune(M.S.)India.
}

\begin{abstract}
In this action research study, where the subjects are our undergraduate grade mathematics students, we try to investigate the impact of direct 'inquisition' instruction on their communication and achievement. We will strategically implement the addition of 'replication' study into each concept of limit over a four-month time period and thus conclusion can be making for the rest of the Mathematics. The students practiced using inquiry in verbal discussions, review activities, and in mathematical problem explanations. We discovered that a majority of students improved their overall understanding of mathematical concepts based on an analysis of the data we collected. We also found that in general, students felt that knowing the definition of mathematical words are important and that it increased their achievement when they understood the concept as a whole. In addition, students will be more exact in their communication after receiving inquiry instructions. As a result of this research, we plan to continue to implement inquisition into daily lessons and keep replication communication as a focus of the mathematics class.
\end{abstract}

Keywords: Concept of Limits, $\varepsilon-\delta$ definition of Limit.

\section{Outline of Article:}

This paper is organized in five sections. We begin with very brief descriptions of our introduction and research paradigm and our practical perspective which we refer to as the IOA-R Model Fig.1 [1].The subsequent sections are the heart of the paper. They consist of the understanding of definition of limit concept and followed by problem solving without the actual understanding or applying the said concept. Finally, we suggest some pedagogical suggestions for that could relate to how the limit concept can be learned in correlation with IOA-R model and hoping that this IOA-R model can be applied to the rest fields of Mathematics.

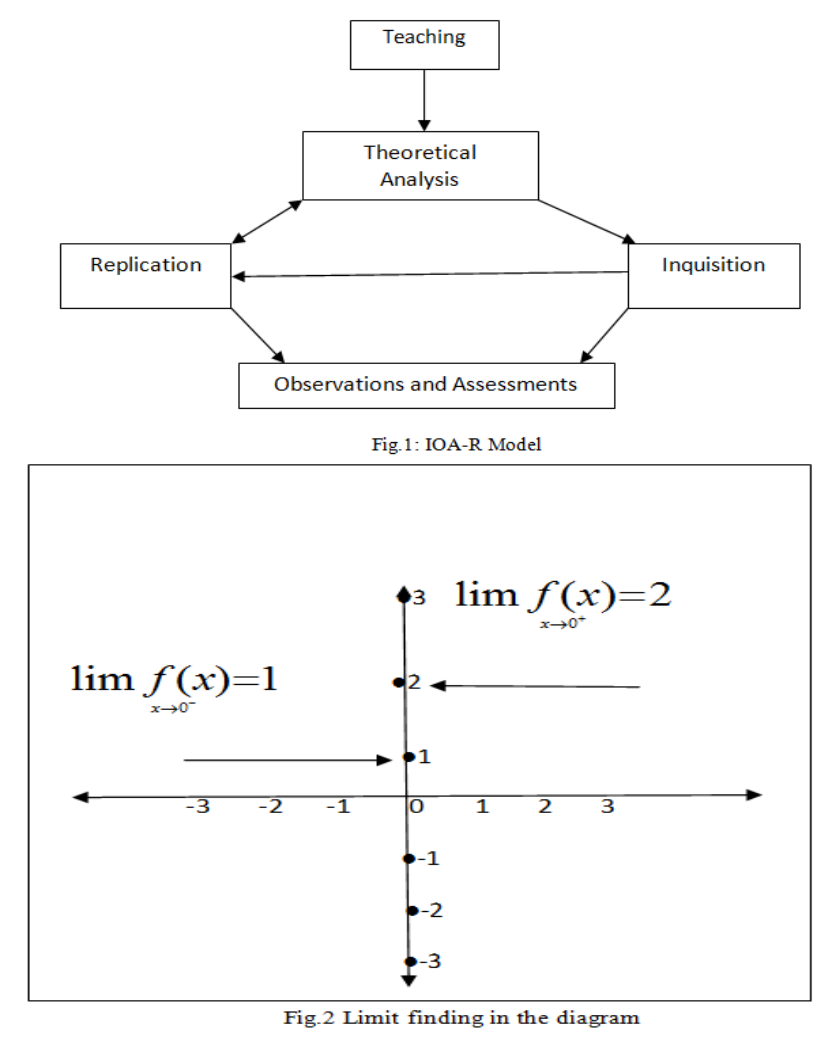


As an example Fig. 2 for the function defined as follows:

$$
\begin{aligned}
f(x) & =1, \text { for } x \leq 0 \\
& =2 \text { for } x>0
\end{aligned}
$$

The students usually solves the problem straightforward,

$$
\underset{x \rightarrow 0^{-}}{\operatorname{Limf}(x)=1, \quad \operatorname{Limf}(x)=2} \quad
$$

and both sided limits does not equal and hence limit does not exist, rather if you go through while solving each problem, even the case of $\varepsilon-\delta$ definition of Limit. It will be more understandable for the poor student in mathematics too. Further, the same strategy can be applied to the rest of Mathematics.

\section{Purpose Statement}

Communication within mathematics class promotes higher-level thinking skills [3].Inquisition and replication can be an alternative to today's typical lecture teaching methods [2].One purpose of our study is to see how much student's uses mathematical inquiry after receiving direct instruction. We want to see how much the inquiry instruction influenced their problem explanations. Another purpose of the study is to see the effect of replication instruction on mathematical understanding and achievement. We want to explore the idea that when students use the correct inquiry being used repeatedly and then inquiry is the major focus of instruction, then the greater understanding of mathematics concepts might take place. The last purpose of our study is to see how our teaching shall be changed when we put such a major focus on inquiry and replication communication. Obviously, we know there would be changes in the timing and organization of the topics, but we are not sure what further impacts this research would have on our delivery of the material. One study that focused on the implementation of a vocabulary-based curriculum found that those students who had more exposures to the vocabulary words were more successful [4].

\section{Method}

Our data will come in a variety of different forms and will be collected in multiple ways, viz. Questionnaires on Limit theory by Students, Books on mathematics, Books on mathematics Education and Science Education, Research Articles regarding Limit Theory. The first part of our data collection may be to record achievement information, before the focus on inquiry and written expression began. We will use data based on class work, quizzes, chapter test, and criterion-referenced tests. We want to see how much students achieved using an individual-concept focus, as we did at the beginning of the college year. We will organize this information in a spreadsheet so that we could easily see progress. We will label each student individually, as well as find the mean across students for each type of data.

The next kind of data that we will collect is a writing sample. We will give the students a problem over concept of the Limit that we had already covered. We will ask them to solve the problem and explain their process. This allows us to see where each student is in the inquiry and reply process and give us a great starting point for our teaching.

\section{Pedagogical Suggestions:}

The main pedagogical suggestion that we will make based on the considerations in this paper has to do with constructing a "Inquisition" and "Replication" strategies. We propose certain class activities that could help students can construct an inquisition separately and then, in their minds, use to construct the replication.

To help achieve this, we are going to use, 1) Design the experiment with the help of Principle of Replication, 2) To test the effectiveness of Principle of Replication.

\section{Social Utility:}

The outcome (Product) of this paper work will help all the fields where Calculus and specially Limit Theory are applied. It will also be useful for Undergraduate mathematics students, teachers and researchers.

\section{References}

[1]. Chris Rasmussen: An inquiry oriented Approach to undergraduate mathematics. The Journal ofMathematical Behavior, Vol. 26, Nov.3, (2007).

[2]. Borasi, R. \& Rose, B. (1989). Journal writing and mathematics instruction. EducationalStudies in Mathematics, 20(4), $347-365$.

[3]. Zaslavsky, O. \& Shir, K. (2005). Students' conceptions of a mathematical definition.Journal for Research in Mathematics Education, 36(4), 317-346.

[4]. Zimmerman, C. (1997). Do reading and interactive vocabulary instruction make a difference? An empirical study. TESOL Quarterly, 31(1), 121-140. 